\title{
EFFECT OF PEER-BASED INTERVENTION ON UNWANTED PREGNANCY PREVENTION BEHAVIOR IN ADOLESCENTS: A META-ANALYSIS
}

\author{
Denanda Agnes Safitri'), Setyo Sri Rahardjo²), Bhisma Murti1) \\ 1)Masters Program in Public Health, Universitas Sebelas Maret \\ ${ }^{2)}$ Faculty of Medicine, Universitas Sebelas Maret
}

\begin{abstract}
Background: Prevalence of adolescents' unwanted pregnancy is relatively high in Asia (43\%), Africa (45\%), and both Latin America and Caribbean (74\%). Unwanted pregnancy at an early age is correlated with social consequences as well as increased health risks for both mother and infants. Peer-based intervention is a program to promote sexual and reproductive health, including the prevention of unwanted pregnancy. This study aimed to assess the influence of peer-based intervention on unwanted pregnancy prevention behaviors in adolescents.

Subject dan Method: Meta-analysis was conducted based on PRISMA guidelines. Articles with randomized controlled trial design published in 2000-2020 were included for meta-analysis. These articles were searched from PubMed, Science Direct, Research Gate, and Google Scholar databases. Keyword used "peer education" OR "peer led" OR "peer counseling” OR “peer approach" OR "peer teaching” OR "peer mentoring” AND "unwanted pregnancy" AND adolescent AND "randomized controlled trial". Articles that met eligibility criteria were analyzed using Revman $5 \cdot 4$.

Results: Ten articles met the criteria for a meta-analysis with sample size 15,439. This study showed that peer-based intervention $(\mathrm{RR}=1.12 ; 95 \% \mathrm{CI}=0.95$ to $1.32 ; \mathrm{p}=0.160)$ improved unwanted pregnancy prevention behavior in adolescents, but it was statistically non-significant.
\end{abstract}

Conclusion: Peer-based intervention improves unwanted pregnancy prevention behavior in adolescents, but it is statistically non-significant.

Keywords: peer-based intervention, unwanted pregnancy, adolescents

\section{Correspondence:}

Denanda Agnes Safitri. Masters Program in Public Health, Universitas Sebelas Maret, Jl. Ir. Sutami 36A, Surakarta 57126, Central Java, Indosesia. Email: denandagnesafitri@gmail.com. 